\title{
Effects of Strain and Contents of Impurity Elements on Center-line Crack Susceptibility in Laser Beam Welds of Type 316L Stainless Steel*
}

\author{
by Hideki Mitsunari**, Hiroaki Mori***, Satoshi Kon**** and Masakazu Shibahara*****
}

\begin{abstract}
To make clear the effect of strain occurred in weld metal of Type 316L stainless steel during laser beam welding (LBW) on center-line cracking in LBWs, side-bead test was adopted to evaluate the susceptibility by measurement of the crack length. The stainless steels varied with impurity elements such as P and S were used as the materials for the test. From the side-bead test, the crack length decrease with increase in the laser welding velocity. Compared with high and low amounts of impurity elements, the crack length occurred in welds metals with higher contents of impurity elements were remarkably longer than those in lower ones. To discuss the phenomena, the thermal-elastic-plastic FEM analysis considering with temperature dependent interface element has been conducted to simulate the side-bead test. From the calculation, the cracking behavior recognized in the actual side-bead test was relatively in accordance with calculation. On the basis of these results, the side-bead test was a useful test method to evaluate the crack susceptibility. In addition, it seems to be suggested that the susceptibility may be possible to predict by the FEM analysis due to use correct physical constants of the materials.
\end{abstract}

Key Words: Laser beam welding, Type 316L stainless steel, Center-line crack, Side-bead test, Impurity element, Thermal elastic-plastic FEM analysis

\section{Introduction}

Type $316 \mathrm{~L}$ austenitic stainless steels are used as structural materials for a lot of pressure vessels in chemical plants, nuclear generation facilities, and so on. Recently, higher reliability for welded joints in these pressure vessels is demanded, to keep safety during these plants' operating. From the viewpoint of new welding method to realize high accuracy in joints, laser beam welding (LBW) has gotten attention in many kinds of industrial fields. However, solidification cracking sometimes occurs in the LBWs of this type of stainless steels. One of the typical morphology of solidification cracking is center-line crack. Moreover, it's well known that the risk of solidification crack is raised especially in the case of the weld metal solidified with primary austenite. In addition, the primary austenite solidification occurs sometimes in LBW for the austenitic stainless steel, when heat input has been suppressed under certain values. Center-line cracking might take place with small amount of strain, as the weld metal has been in brittle due to full austenite formed in weld metal of LBWs. Therefore, in order to make clear the effect of strain occurred in weld metal of Type 316L stainless steel during laser beam welding on center-line cracking, the side-bead test ${ }^{1), 2)}$ was

\footnotetext{
*Received: 2014.11.28

${ }^{* *}$ Student Member, Graduate School of Engineering, Osaka University

${ }^{* * *}$ Member, Graduate School of Engineering, Osaka University

**** Student Member, College and Graduate School of Engineering, Osaka Prefecture University

${ }^{* * * * *}$ Member, College and Graduate School of Engineering, Osaka Prefecture University
}

adopted in this study, to evaluate the crack susceptibility. And to clarify the effect of impurity elements on center-line cracking susceptibility in LBWs, two kinds of type 316L stainless steels were used in this study.

\section{Materials and experimental procedure}

\subsection{Materials}

In order to clarify the effects of impurity elements (P and $\mathrm{S}$ ) on center-line crack susceptibility in LBWs, two kinds of type 316L austenitic stainless steels varied in contents of these impurity elements were used in this study. The chemical compositions of the materials are indicated in Table 1. One is the laboratory-melted material with remarkably low contents of impurity elements, SUS316L-J, and the other is deliberately added high amount of impurity elements, SUS316L-S.

\subsection{Experimental procedure}

The side-bead test was used for evaluation of solidification crack susceptibility. Schematic illustration of the side-bead test specimen is shown in Fig. 1. The material plates were prepared with the dimensions of $200 \mathrm{~mm} \times 40 \mathrm{~mm} \times 3 \mathrm{~mm}$. In this test, laser beam was irradiated at the edge of $4 \mathrm{~mm}$ distance from the corner of specimens. The distance has been decided by pre-test to find the crack initially occurred at the center of weld metal. Conditions for LBW used in the current research were as follows. The laser power and beam diameter were $4 \mathrm{~kW}$ and $0.6 \mathrm{~mm}$, 
respectively. Shielding gas was argon and was used at a constant flow rate of $20 \mathrm{~L} / \mathrm{min}$. To evaluate the effect of welding velocities on the center-line crack susceptibility, welding velocity in the side-bead test was varied from $1.2 \mathrm{~m} / \mathrm{min}$ to $3.6 \mathrm{~m} / \mathrm{min}$ and the length of center-line cracks occurred in weld metal was measured using a digital microscope. In this experiment, crack lengths were used as the parameters which evaluate crack susceptibility.

Table 1 Chemical compositions of materials used (mass \%)

\begin{tabular}{|c|c|c|c|c|c|c|c|c|c|c|}
\hline Alloy & $\mathrm{C}$ & $\mathrm{Si}$ & $\mathrm{Mn}$ & $\mathrm{Ni}$ & $\mathrm{P}$ & $\mathrm{S}$ & $\mathrm{Cr}$ & $\mathrm{Mo}$ & $\mathrm{N}$ & $\mathrm{Fe}$ \\
\hline SUS316L-J & 0.012 & 0.55 & 1.12 & 14.0 & 0.0006 & 0.0008 & 16.8 & 2.30 & 0.0298 & Bal. \\
\hline SUS316L-S & 0.017 & 0.67 & 0.99 & 12.1 & 0.0300 & 0.0030 & 17.3 & 2.05 & - & Bal. \\
\hline
\end{tabular}

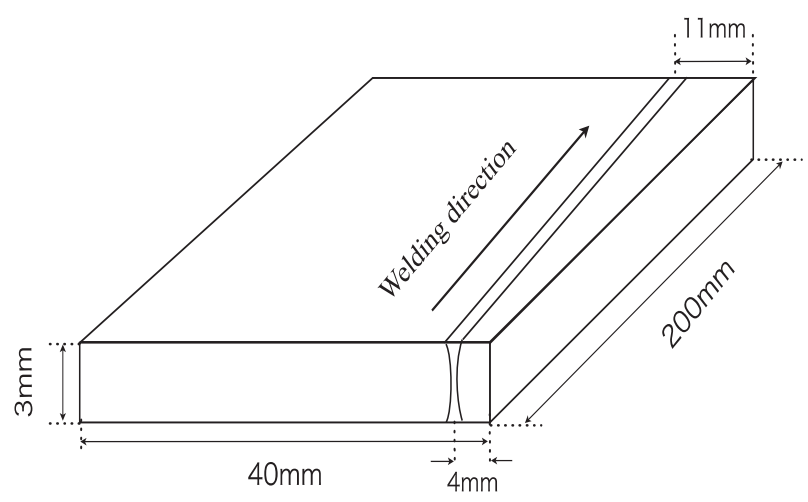

Fig. 1 Schematic illustration of the side-bead test specimen

\section{Experimental result}

\subsection{Observation of bead appearance, cross section and} fractured surface

In order to verify that the cracks occurred in weld metal were center-line crack, we observed bead appearance, cross section and fractured surface of the specimen after side-bead test. Fig. 2 shows bead appearance of specimen. As indicated in the Fig. 2, all the cracks occurred at the center of bead, and passed through from the surface to the back side in this study. Fig. 3 and Fig. 4 shows the picture of cross section and fractured surface, respectively. From Fig. 3, it can be seen that solidification organization become cellular or cellular dendrite structure. Dendrite has grown from both side to the center of the bead, and hit each other at the center of the bead. From Fig. 4, it was found that the fractured surface had primary and secondary dendrite arms and smooth surface. It seems that molten metal existed at the moment of cracking.

It follows from these observation results that all cracks in this study were confirmed center-line crack.
Table 2 Welding conditions

\begin{tabular}{|c|c|}
\hline Laser power $[\mathrm{kW}]$ & 4.0 \\
\hline Focusing position & surface of specimen \\
\hline Welding velocity $[\mathrm{m} / \mathrm{min}]$ & $1.2,1.5,1.8,2.1$, \\
& $2.4,2.7,3.0,3.3,3.6$ \\
\hline Spot diameter $[\mathrm{mm}]$ & 0.6 \\
\hline Shield gas & $\mathrm{Ar}$ \\
\hline Shield gas flow rate $[\mathrm{L} / \mathrm{min}]$ & 20 \\
\hline
\end{tabular}

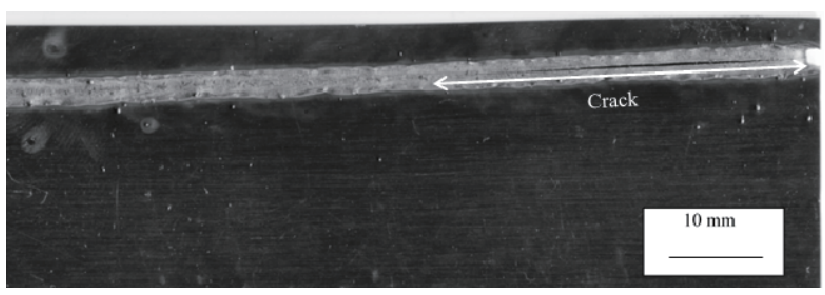

Fig. 2 Surface appearance of specimen after side-bead test in a side-bead specimen
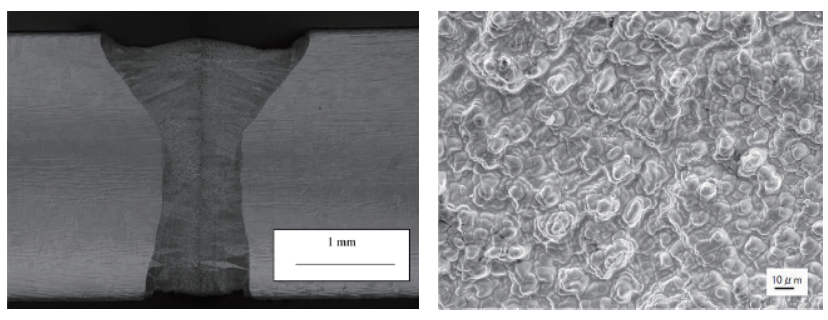

Fig. 3 Cross-sectional view of laser welded bead

Fig. 4 Typical SEM image of fracture surface of crack

\subsection{Effect of welding speed on bead shape}

We observed cross section of the specimen after side-bead test because this was also important in order to determine the shape of the heat source used in the thermal elastic-plastic analysis. Table 3 shows cross section of the bead against each welding speed. The width lengths of the wine-cup bead shape increase with decrease in the laser 
welding speeds.

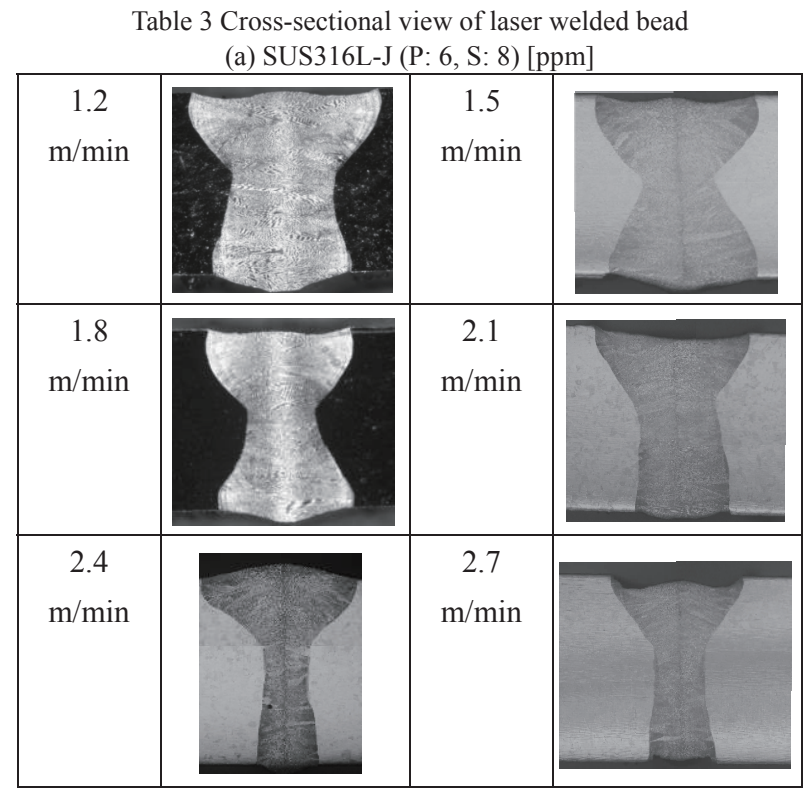

Table 3 Continued (b) SUS316L-S (P: 300, S: 30) [ppm]

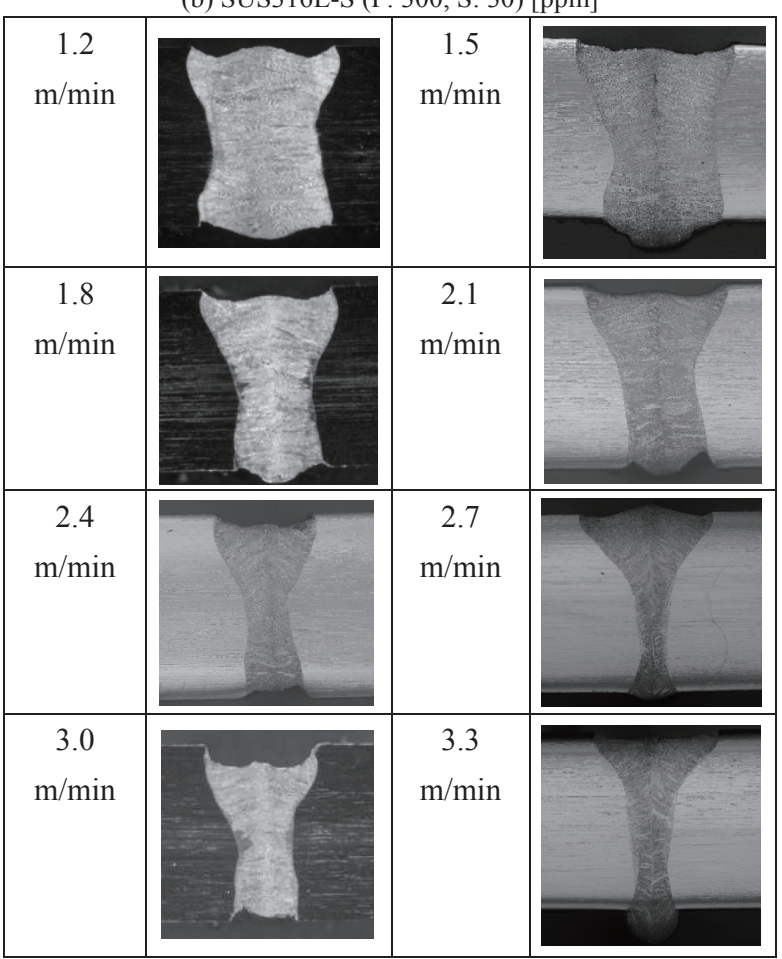

\subsection{Effect of welding condition on crack length}

The result of side-bead test is shown in Fig. 5. Since it didn't make the keyhole for full penetrate when the welding speeds were $3.6 \mathrm{~m} / \mathrm{min}$ and over, we figured that the conditions of $3.6 \mathrm{~m} / \mathrm{min}$ and over were inadequate, in the conditions of Steel S. In the case of steel $\mathrm{J}$, the solidification crack occurred when the welding speeds were $1.2 \mathrm{~m} / \mathrm{min}$ and over and $2.4 \mathrm{~m} / \mathrm{min}$ and less. In the case of steel $\mathrm{S}$, the solidification crack occurred $2.4 \mathrm{~m} / \mathrm{min}$ and less. The longest crack occurred at a speed of $2.4 \mathrm{~m} / \mathrm{min}$ in steel $\mathrm{S}$, and the longest crack occurred at a speed of $1.5 \mathrm{~m} / \mathrm{min}$ in steel J. From the side-bead test, the center-line crack lengths decrease with increase in the laser welding velocities. Compared with high and low amounts of impurity elements, the crack lengths occurred in weld metal of the materials with higher contents of impurity elements were remarkably longer than those in lower impurity contents ones. From these results, to decrease impurity elements will be useful technique to decrease solidification crack susceptibility. And to decrease heat input will be also useful to decrease solidification crack susceptibility.

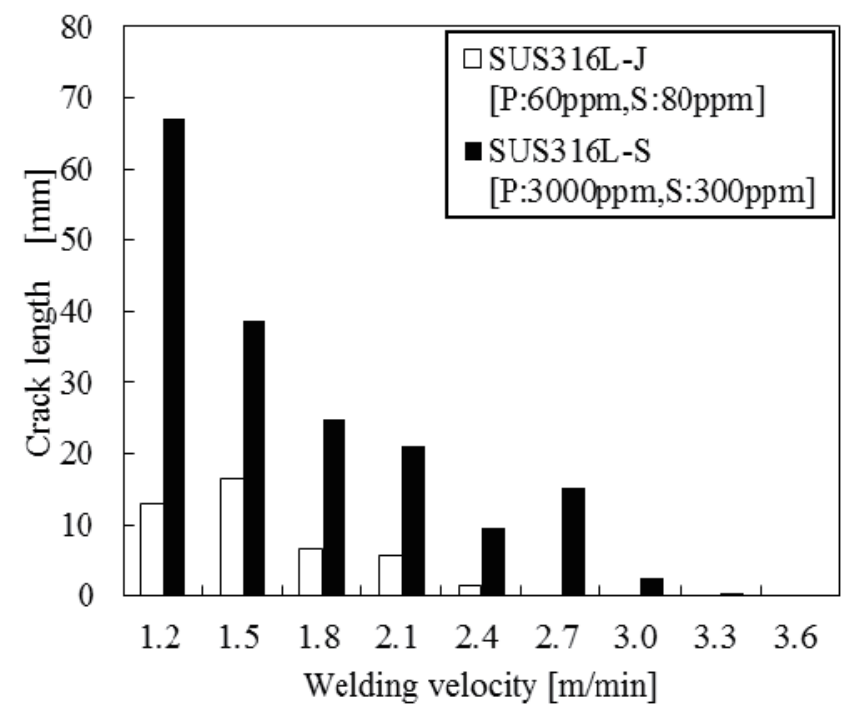

Fig. 5 Relationship between welding velocity and crack length measured by the side-bead test

\section{Calculation model}

To discuss the cracking behavior in the side-bead test, the thermal elastic-plastic FEM analysis with considering the temperature dependent interface element ${ }^{3)-5)}$ has been conducted to simulate the side-bead test on a computer.

Fig. 6 indicates the physical constants with thermal effects for calculation. Schematic illustration of the numerical analysis model is shown in Fig. 7. To simulate the side-bead test, the mesh model is more finely at the weld line. The analysis condition are same as the actual side-bead test. The value of heat source for calculation were calculated by the penetration shape of the specimen after actual side-bead test. The value of heat source whose bead width corresponded with the bead width of the experiment were used for calculation.

In this calculation, to examine the affection by the difference of brittle temperature range (BTR) ${ }^{6}$ ) related to impurity elements' 
contents, the range was varied in two grades (100 K (BTR 100) and $150 \mathrm{~K}$ (BTR 150)).

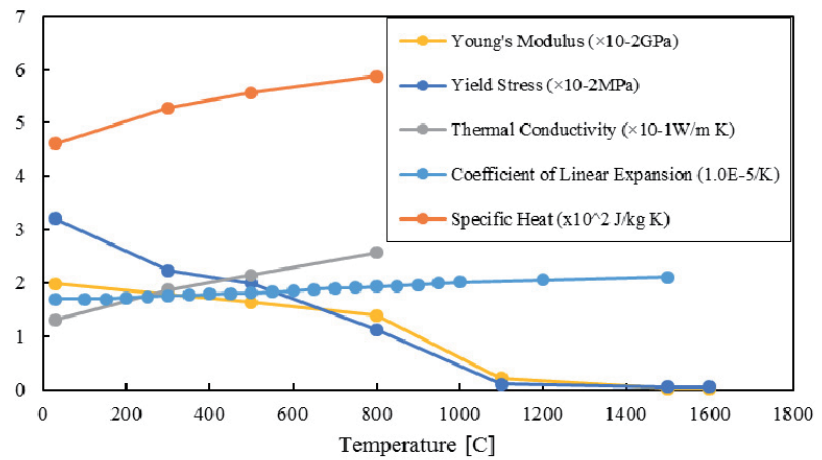

Fig. 6 Physical constants considering with thermal effects for calculation

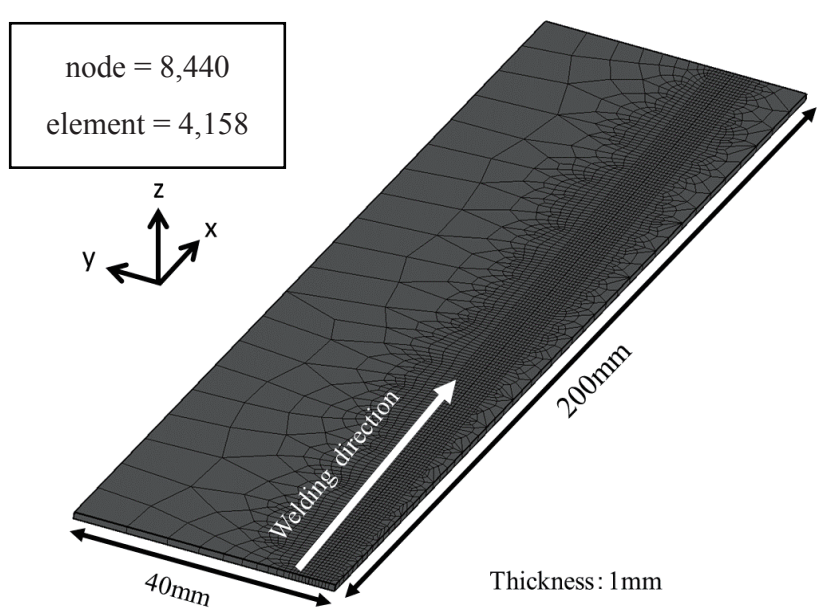

Fig. 7 Schematic illustration of the numerical analysis model

\section{Calculation result}

Schematic illustration of the calculation result is shown in Fig. 8. Fig. 9 shows the relationship between welding velocities and crack lengths calculated by the numerical analysis model. From the calculation, the cracking behavior simulated the crack test by the numerical analysis were in accordance with that in the actual side-bead test. Fig.10 shows the relation between the crack length of calculation with the BTR value of $100 \mathrm{~K}$ (BTR 100) and the crack length of measurement (Steel S). From this graph, calculated crack length is relatively according with measurement. The calculation method used in this study could comparatively indicate the actual side-bead test. On the basis of these results, the side-bead test is useful to evaluate center-line crack susceptibility. In addition, it seems to be suggested that the crack susceptibility may be predicted by the FEM analysis with using correct physical constants of the materials.
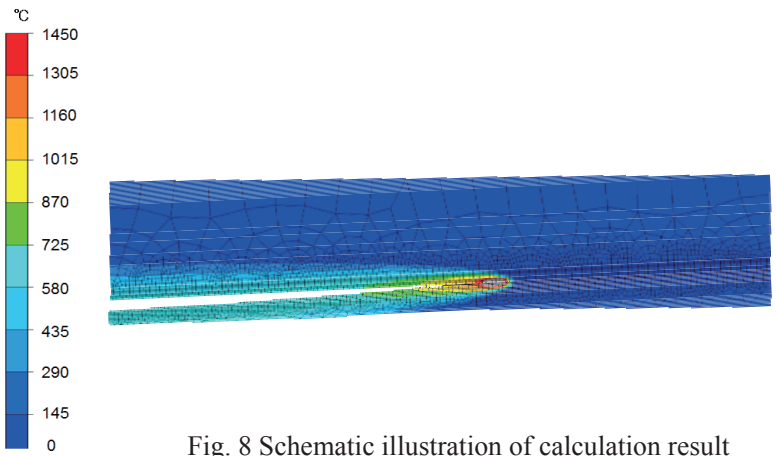

Fig. 8 Schematic illustration of calculation result

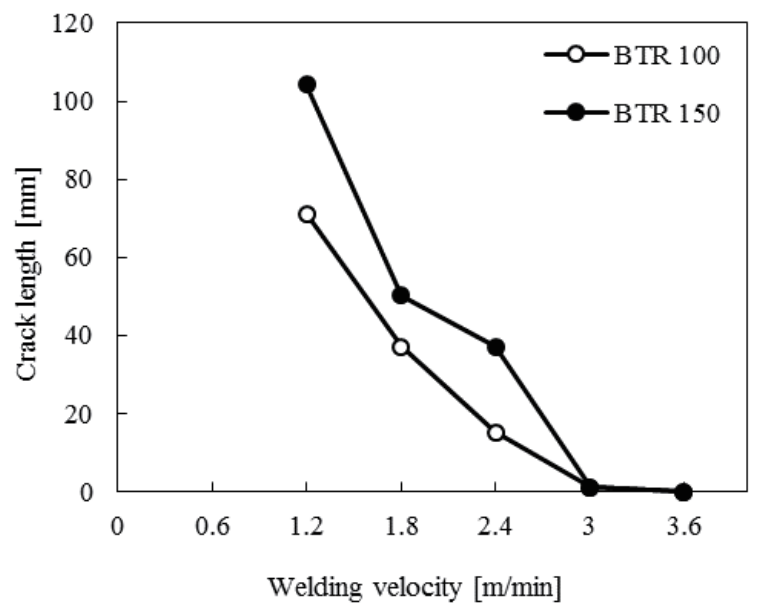

Fig. 9 Relationship between welding velocity and crack length calculated by the thermal elastic-plastic analysis with temperature dependent interface element

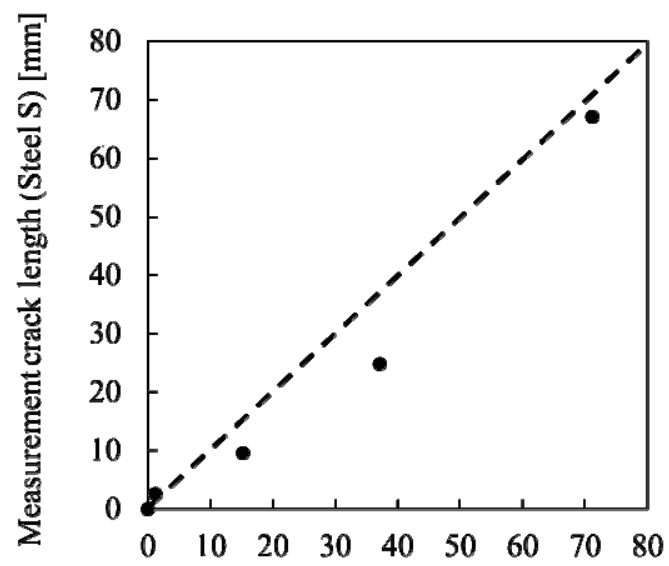

Calculated crack length (BTR 100) [mm]

Fig. 10 Relationship between crack length of calculation and measurement 


\section{Conclusion}

To make clear the effect of strain occurred in weld metal of Type $316 \mathrm{~L}$ stainless steel during laser beam welding on center-line cracking in LBWs, the side-bead test was adopted in this study, to evaluate the crack susceptibility. In addition, to discuss the cracking behavior in the side-bead test, the thermal elastic-plastic FEM analysis considering with temperature dependent interface element was conducted to simulate the test on a computer. From experimental results, it was obviously recognized that the center-line crack lengths decrease with increase in welding velocities, and the crack lengths occurred in weld metal of the materials with higher contents of impurity elements were much longer than those in lower impurity contents ones in the case of same welding velocity. Calculation revealed that the cracking behavior simulated the cracking test by the numerical analysis using adequate physical constants was in accordance with that in the actual side-bead test. On the basis of these results, the side-bead test is useful to evaluate center-line crack susceptibility. In addition, it seems to be suggested that the crack susceptibility may be predicted by the FEM analysis with using correct physical constants of the materials.

\section{Reference}

1) X. Luo, Preprints of the National Meeting of JWS, 68, (2004-1).

2) K. Shidou, Preprints of the National Meeting of JWS, 72, (2003-4).

3) M. Shibahara, H. Serizawa, H. Murakawa, Journal of the Kansai Society of Naval Architect Japan, 232, 135-144 (1999).

4) M. Shibahara, H. Serizawa, H. Murakawa, Journal of the Kansai Society of Naval Architect Japan, 233, 149-155 (2000).

5) M. Shibahara, H. Serizawa, H. Murakawa, Journal of the Kansai Society of Naval Architect Japan, 235, 161-169 (2001).

6) T. Senda, F. Matsuda, G. Takano, K. Watanabe, T. Kobayashi, T. Matsuzaka, Journal of the Japan Welding Society, 41, 709-723 (1972-6) 